\title{
Effect of HLA mismatch on acute graft-versus-host disease
}

\author{
Junya Kanda
}

Received: 17 June 2013/Revised: 11 July 2013/Accepted: 16 July 2013/Published online: 28 July 2013

(c) The Japanese Society of Hematology 2013

\begin{abstract}
HLA matching between donors and recipients is the most important factor associated with acute graftversus-host disease (GVHD) following allogeneic hematopoietic stem cell transplantation. With improvements in GVHD prophylaxis and supportive care, transplantations from HLA mismatched donors are performed increasingly frequently, drawing greater attention to the effects of HLA mismatch. In related transplantation, HLA 1-antigen mismatch at the HLA-A, HLA-B, and HLA-DR loci is considered acceptable, but the incidence of severe acute GVHD under standard prophylaxis is higher than that for matched related and unrelated transplantation, highlighting the need for a modification of GVHD prophylaxis. Development of new GVHD prophylaxes has now made HLA 2-3-antigen mismatched related transplantation feasible, and has almost overcome the HLA barrier. In unrelated bone marrow or peripheral blood stem cell transplantation, donors matched for HLA-A, HLA-B, HLA-C, and HLA-DRB1 alleles are the most preferable. The impact of allele or antigen mismatch has been evaluated in a number of studies, but the results of these have not been consistent, partly due to differences in race and HLA distribution. The effects of HLA mismatch may differ depending on the year of transplantation and the form of GVHD prophylaxis administered. In cord blood transplantation, successful transplantation can be achieved with up to two HLA mismatches. In children, compared to the use of HLA mismatched units, the use of HLA-matched units is associated with a lower risk of acute GVHD and
\end{abstract}

\section{J. Kanda $(\square)$}

Division of Hematology, Saitama Medical Center,

Jichi Medical University, 1-847 Amanuma-cho,

Omiya-ku, Saitama, Saitama 330-8503, Japan

e-mail: jkandajp@gmail.com mortality, while in adults HLA mismatches may have a lower impact on outcome. Thus, the effect of HLA matching should be evaluated separately for different stem cell sources.

Keywords HLA antigen mismatch - HLA allele mismatch · Acute graft-versus-host disease . Overall survival · Graft-versus-host direction . Host-versus-graft direction

\section{Introduction}

An HLA-identical sibling is the ideal donor in allogeneic hematopoietic stem cell transplantation (HSCT) because the risk of allo-immune complications is directly correlated to the number of HLA mismatches between donor and recipient [1-3]. The effects of the immune reaction caused by HLA mismatch differ depending on whether the mismatch is in the graft-versus-host $(\mathrm{GVH})$ or host-versus-graft (HVG) direction. The presence of HLA mismatches in the GVH direction is associated with a higher incidence of graft-versus-host disease (GVHD), as a mismatched antigen in the GVH direction can be a major target for donor T cells. On the other hand, the presence of HLA mismatches in the HVG direction is associated with a higher incidence of rejection, as a mismatched antigen in the HVG direction can be a major target for the remaining recipient $\mathrm{T}$ cells.

For patients who lack an HLA-identical sibling, an HLA-matched unrelated donor (MUD) is the preferred alternative donor [4-6]. Outcomes of HSCT from HLA-A, HLA-B, and HLA-DR antigen-matched MUD were inferior to those of HSCT from an HLA-identical sibling, due to the high incidence of severe acute GVHD and treatmentrelated mortality [3]. However, thanks to an improved 
understanding of the importance of HLA matching at the allele level for HLA-A, HLA-B, HLA-C, and HLA-DRB1/ DQB1 loci, the outcomes of MUD transplantation have significantly improved and now are comparable to those of HSCT from an HLA-identical sibling [7-9].

Thus, HLA matching is of utmost importance for better outcomes following HSCT, although it is difficult to find an MUD for patients with rare HLA haplotypes. Recently, unrelated cord blood (UCB) has emerged as a promising alternative source for both pediatric and adult patients [1014]. In UCB transplantation (UCBT) with standard GVHD prophylaxis, the incidence of acute GVHD was comparable to or even lower than that in HSCT from an HLA-identical sibling or HLA-MUD despite multiple HLA mismatches between recipients and UCB units, suggesting that the HLA barrier may differ by stem cell source. In this review, we will discuss the effect of HLA mismatch on acute GVHD risk for different stem cell sources.

\section{Effects of HLA mismatch in related transplantation}

\section{HLA 1-antigen mismatched related transplantation}

The impact of HLA mismatch in the GVH or HVG direction in related HSCT was first shown by Anasetti et al. $[1,2]$. They analyzed data from 1,248 patients who received transplants from HLA-matched or mismatched related donors between 1975 and 1986, with a GVHD prophylaxis of only methotrexate or a combination of methotrexate and cyclosporine. The incidence of severe acute GVHD increased with the degree of HLA mismatch, particularly in patients who received GVHD prophylaxis of only methotrexate, and led to a high incidence of treatment-related mortality. However, because the incidence of relapse was lower in the HLA 1-antigen mismatch group than in the HLA-identical sibling group, the survival rate in the HLA 1-antigen mismatch group was nearly the same as that in the HLA-identical sibling group. In Japan, Kanda et al. [3] analyzed data from 2,947 patients who underwent related HSCT for leukemia or myelodysplastic syndrome between 1991 and 2000 using the Japan Society for Hematopoietic Cell Transplantation (JSHCT) database. The presence of HLA antigen mismatch was identified as an independent risk factor for the development of grade 3-4 acute GVHD and decreased survival. The impact of HLA mismatch on survival was more apparent in the standard-risk patients. One-antigen mismatch had little effect on survival in the high-risk patients, which is in concordance with the findings of a previous study [1]. Survival after HSCT from an HLA-1 antigen mismatched related donor was the same as that after HSCT from an HLA-A, HLA-B, and HLA-DR antigen-matched MUD in either the standard-risk or high-risk group (Table 1). According to these findings, a single-antigen mismatched related donor is considered to be a good alternative donor to an MUD when immediate HSCT is necessary.

Transplant procedures and supportive care continue to improve, and thus the results of previous studies may not reflect the current situation. Furthermore, the outcomes of single-antigen mismatch-related HSCT were compared to those from a HLA-A, HLA-B, and HLA-DR antigen-matched MUD in a previous Japanese study [3], as information on HLA allele matching in unrelated transplantation was insufficient at that time. Therefore, we compared the clinical outcomes of transplantation from a related donor with an

Table 1 Summary of studies comparing outcomes of transplantations from an HLA 1-antigen-matched related donor and a matched unrelated donor

\begin{tabular}{|c|c|c|c|c|c|c|c|}
\hline References & $\begin{array}{l}\text { No. of } \\
\text { transplantations }\end{array}$ & $\begin{array}{l}\text { Year of } \\
\text { transplantation }\end{array}$ & $\begin{array}{l}\text { Median age } \\
\text { (range), years }\end{array}$ & Disease & Conditioning & $\begin{array}{l}\text { Grade } 3-4 \text { acute } \\
\text { GVHD }\end{array}$ & Overall survival \\
\hline $\begin{array}{l}\text { Kanda et al. } \\
\text { [3] }\end{array}$ & $\begin{array}{l}86 \text { from 1AG } \\
\text { MMRD } \\
987 \text { from 6/6 } \\
\text { AG MUD }\end{array}$ & 1991-2000 & NA ( $\geq 16$ years) & $\begin{array}{l}\text { AML/ALL/ } \\
\text { CML/MDS }\end{array}$ & NA & $\begin{array}{r}\text { 1AG MMRD > } \\
6 / 6 \text { AG MUD }\end{array}$ & $\begin{array}{l}\text { 1AG MMRD }=6 / 6 \\
\text { AG MUD }\end{array}$ \\
\hline $\begin{array}{l}\text { Kanda et al. } \\
\text { [9] }\end{array}$ & $\begin{array}{l}327 \text { from } 1 \mathrm{AG} \\
\text { MMRD } \\
452 \text { from } 8 / 8 \\
\text { AL MUD }\end{array}$ & 2001-2008 & $\begin{array}{l}\text { 1AG MMRD: } \\
45 \text { (16-69) } \\
\text { 8/8 AL MUD: } \\
48 \text { (16-68) }\end{array}$ & $\begin{array}{l}\text { AML/ALL/ } \\
\text { CML/MDS }\end{array}$ & MAC/RIC & $\begin{array}{l}\text { 1AG MMRD > } \\
\text { 8/8 AL MUD }\end{array}$ & $\begin{array}{l}\text { 1AG MMRD <8/8 } \\
\text { AL MUD } \\
\text { (standard risk) }\end{array}$ \\
\hline $\begin{array}{l}\text { Valcarcel } \\
\text { et al. [16] }\end{array}$ & $\begin{array}{l}89 \text { from } 1 \text { AG } \\
\text { MMRD } \\
700 \text { from } 8 / 8 \\
\text { AL MUD }\end{array}$ & 1995-2005 & $\begin{array}{l}\text { 1AG MMRD: } \\
35 \text { (18-64) } \\
\text { 8/8 AL MUD: } \\
43 \text { (18-74) }\end{array}$ & $\begin{array}{l}\text { AML/ALL } \\
\text { (CR1/CR2) }\end{array}$ & MAC/RIC & $\begin{array}{l}\text { 1AG MMRD = } \\
\text { 8/8 AL MUD }\end{array}$ & $\begin{array}{l}\text { 1AG MMRD }=8 / 8 \\
\text { AL MUD }\end{array}$ \\
\hline
\end{tabular}

IAG MMRD HLA 1-antigen mismatched related donor, $A L M U D$ allele-matched unrelated donor, $N A$ not available, $A M L$ acute myelogenous leukemia, $A L L$ acute lymphoblastic leukemia, $C M L$ chronic myelogenous leukemia, $M D S$ myelodysplastic syndrome, $C R$ complete remission, $M A C$ myeloablative conditioning, $R I C$ reduced-intensity conditioning 
HLA single-antigen mismatch at the HLA-A, HLA-B, or HLA-DR locus in the GVH direction (RD/1AG-MM-GVH) $(n=327)$ and that with an HLA $8 / 8$ allele (HLA-A, HLA-B, HLA-C, and HLA-DRB1) MUD (8/8 MUD) $(n=452)$ [9] (Table 1). The overall survival was significantly lower in the RD/1AG-MM-GVH group than in the 8/8 MUD group due to the increase in non-relapse mortality, particularly in the standard-risk group. The incidence of severe acute GVHD was significantly higher in the RD/1AG-MM-GVH group, with a major difference found in the rate of GVHD as the primary cause of death between the two groups (8/8 MUD $4.4 \%$ vs. RD/1AG-MM-GVH $16.9 \%$ ). We then analyzed the impact of different types of antigen mismatch on clinical outcome. We found that HLA-B mismatch was associated with a lower overall survival and higher non-relapse mortality in the standard-risk group, but showed no effect on relapse incidence. Transplantation cases with an HLA-B mismatch tended to have an additional HLA-C mismatch due to linkage disequilibrium, which may explain the lower survival rate in the HLA-B mismatch group. However, as the incidence of severe acute GVHD did not vary based on the mismatch antigen, the reason for the high non-relapse mortality seen in the HLA-B mismatch group remains unknown.

We also compared the clinical outcomes of HSCT from RD/1AG-MM-GVH and UCB [15]. Although the survival rates were comparable between the two groups, the nonrelapse mortality rate was significantly higher in the RD/ 1AG-MM-GVH group, due to the higher incidence of acute and chronic GVHD. Interestingly, the incidence of acute GVHD in the RD/1AG-MM-GVH group-administered anti-thymocyte globulin (ATG) was comparable to that in the UCB group. Furthermore, the survival rate tended to be higher in the RD/1AG-MM-GVH group than in the UCB group, probably due to a comparable GVHD incidence and a lower incidence of graft failure or infection in the RD/ 1AG-MM-GVH group. The adverse effect of the HLA-B mismatch on survival disappeared in the RD/1AG-MMGVH group-administered ATG, suggesting that HLA-B mismatch may have induced an allo-immune reaction and related complications in the RD/1AG-MM-GVH group.

In contrast to our findings, Valcarcel et al. analyzed HSCT reported to the Center for International Blood and Marrow Transplant Research (CIBMTR) between 1995 and 2005. This study compared transplantations from single-antigen mismatch-related donors $(n=89)$ and $8 / 8$ MUDs $(n=700)$ and found no significant difference in survival following transplantation to treat AML and ALL in the first or second complete remission [16] (Table 1). This difference from our results may be partly explained by the fact that, in the Valcarcel study, the MUD group included a significantly smaller number of ALL patients with low-risk cytogenetics. Alternatively, it can be explained by less severe GVHD and a possibly lower rate of GVHD-associated mortality in 8/8 MUD transplantation in the JMDP cohorts due to genetic homogeneity, and potential matching of HLA haplotypes, some of which are highly conserved [17].

Area undetermined in the HLA 1-antigen mismatched related transplantation

As discussed above, HLA matching is usually evaluated at the antigen level for HLA-A, HLA-B, and HLA-DR loci in related HSCT. However, because HLA-B mismatch has an adverse effect on overall survival, HLA-C and HLA-B mismatches should be separately evaluated in the future. Furthermore, allele matching was not considered in two recent studies [9, 16]. Whether the presence of allele mismatch in addition to the single-antigen mismatch (two or more allelic mismatches in total) affects the transplantation outcome is also an important clinical question in transplantation from an RD/1AG-MM-GVH donor. We did not observe a significant effect of the number of allelic mismatches on survival after transplantation from an RD/ 1AG-MM-GVH donor, possibly due to the small sample size [9]. Thus, HLA-C and allelic information is required to elucidate the impact of HLA mismatch in HLA 1-antigen mismatched related HSCT.

A new strategy to overcome the HLA barrier

The probability of identifying an HLA 1-antigen mismatched sibling is only $3 \%$ [18]. A number of approaches have been developed to further expand donor availability and overcome the "HLA barrier". The use of ex vivo T-cell depletion, in vivo T-cell depletion, or post-transplant cyclophosphamide administration enables transplantation from a related donor with multiple HLA mismatches [1925]. Although the risks of relapse and infection are a major problem following HSCT using these methods, transplantation using these methods seems to have overcome the HLA barrier and results in a good clinical outcome for patients who require transplantation, but lack an HLAidentical sibling.

\section{Effects of HLA mismatch in unrelated bone marrow transplantation}

High-resolution typing methods have been able to analyze the DRB1 locus since the 1990s, and several studies published in the 1990s analyzed the effect of DRB1 alleles in HLA antigen-matched MUD transplantation without information on HLA-A and HLA-B allele mismatches [26, 27]. HLA-DRB1 allele mismatch was found to be an independent risk factor for acute GVHD in these studies, 


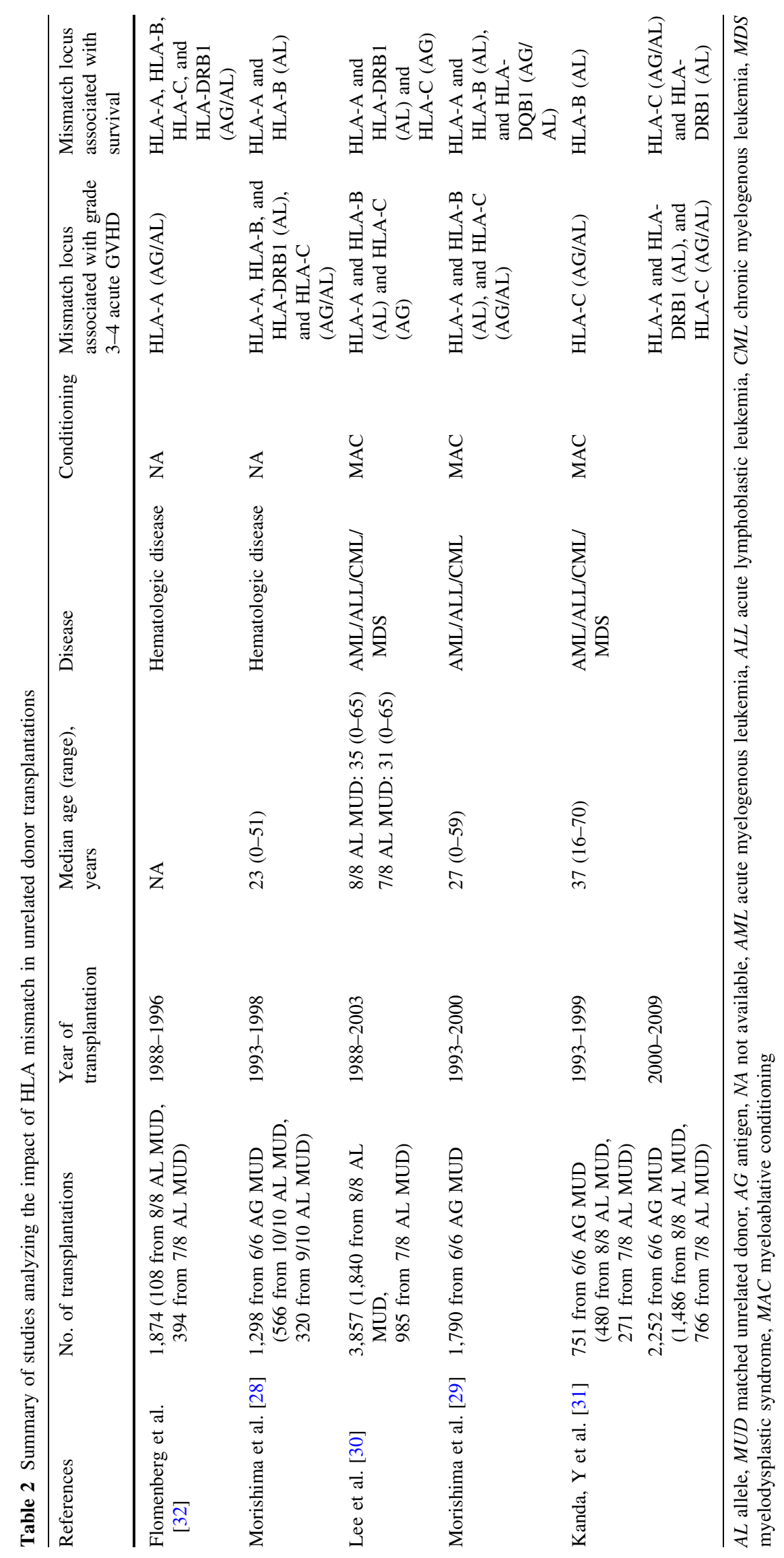


although an undetected HLA-A or HLA-B allele mismatch may have modified the true risk of HLA-DRB1 mismatch. HLA-A and HLA-B allele information became available in the late 1990s, and Sasazuki et al. [28] first analyzed the impact of class I allele mismatches on clinical outcomes. Multivariate analysis revealed HLA-A and HLA-C allele mismatches as independent risk factors for severe acute GVHD. In contrast, class II HLA mismatches did not affect the risk of severe acute GVHD. Morishima et al. [29] expanded the cohort and analyzed 1,298 patients with hematologic diseases who received grafts from an HLA-A, HLA-B, and HLA-DR antigen-matched MUD between 1993 and 1998 (Table 2). They found that a mismatch in the HLA-A, HLA-B, HLA-C, or HLA-DRB1 allele was significantly associated with an increased risk of severe acute GVHD in multivariate analysis, although donors with multiple allele mismatches were included in the analysis. When a single HLA mismatch group was compared with an HLA match group, HLA-DRB1 mismatch was not associated with an increased risk of severe acute GVHD. They further analyzed 1,790 leukemia patients who received a transplant between 1993 and 2000; they reported that HLA-A, HLA-B, and HLA-C, but not HLA-DRB1 mismatch, were associated with severe acute GVHD [30]. HLA-A, HLA-B and HLA-DQB1 mismatches were identified as a risk factor for worse survival. In a recent National Marrow Donor Program (NMDP) study, Lee et al. [31] analyzed 3,857 leukemia patients who received grafts from unrelated donors. In a sub-analysis, they compared the clinical outcome of HSCT from a 7/8 MUD with that from an 8/8 MUD. HLA-A and HLA-B allele mismatches and HLA-C antigen mismatch were associated with an increased incidence of grade 2-4 acute GVHD, but HLADRB1 mismatch was not identified as a risk factor. HLA-A and HLA-DRB1 allele mismatches and HLA-C antigen mismatch were identified as independent risk factors for decreased survival. The different findings of the CIBMTR and JMDP studies, particularly regarding survival, may be due to differences in HLA distribution in different races and the different HLA mismatch combinations at each locus. In addition, inclusion criteria for HLA matching slightly differ. Donors with antigen or allele mismatch for HLA-A, HLA-B, HLA-C, or HLA-DRB1 were included in the CIBMTR study, while donors were HLA-A, HLA-B, and HLA-DR antigen-matched in the JMDP study.

Impact of time of transplantation

The impact of HLA mismatch on GVHD can be influenced or modulated by various patient and transplant backgrounds, particularly the intensity of GVHD prophylaxis, which changed over time. Kanda et al. [32] analyzed 3,003 adult patients who received transplantation from an HLA-
A, HLA-B, or HLA-DR antigen-matched MUD between 1993 and 2009 (Table 2). An HLA-C antigen/allele mismatch was significantly associated with severe acute GVHD in the 1993-1999 period, whereas HLA-A, HLA-B, and HLA-DRB1 allele mismatches were identified as significant risk factors for severe acute GVHD in the 2000-2009 period. In the analysis of survival, HLA-B allele mismatch was associated with worse survival in the early period, whereas HLA-C allele/antigen and HLADRB1 allele mismatches were associated with worse survival in the later period. This study revealed that the impact of a single HLA allele mismatch changed over time, and the negative impact of HLA-DRB1 and HLA-C mismatches became apparent in the more recent cohort. Information on the risk of acute GVHD associated with HLA mismatches at each locus (a high GVHD risk associated with HLA-A and HLA-B allele mismatches and low risk associated with HLA-DRB1 allele mismatches, observed in the early period in Japan) may have prompted physicians to adjust the intensity of GVHD prophylaxis depending on the mismatch locus. Such practice may have contributed to the change in the HLA impact observed in the later period.

Antigen mismatch versus allele mismatch

Allele mismatches are considered more tolerable than antigen mismatches. Flomenberg et al. [33] confirmed this perception in their analysis of NMDP. However, this group included donors with multiple HLA mismatches, and a certain HLA mismatch was compared with an HLA match by adjusting for the presence of other mismatches at other loci. A recent large CIBMTR study has directly compared single-antigen/allele mismatches with 8/8 MUD and reported that the adverse effect of allele mismatches on survival is comparable to that of antigen mismatches, except for HLA-C mismatches [31]. However, evidence based on clinical outcomes in cases of antigen versus allele mismatches in unrelated transplantation is less robust due to the small sample size and heterogeneous backgrounds of study subjects in each antigen or allele mismatch group. Because expansion of donor candidates to single-antigen mismatched donors substantially increases the possibility of finding a donor in an unrelated donor pool and shortens the donor coordination period, external validation of these results in other large registry data is warranted.

High-risk HLA mismatch combinations

The range of HLA mismatch includes various HLA combinations between recipients and donors. Kawase et al. [34] analyzed the impact of HLA mismatch combinations on grade 3-4 acute GVHD and overall survival. They found 
Table 3 Summary of studies analyzing the impact of HLA mismatch in unrelated cord blood transplantations

\begin{tabular}{|c|c|c|c|c|c|c|c|}
\hline References & $\begin{array}{l}\text { No. of } \\
\text { transplantations }\end{array}$ & $\begin{array}{l}\text { Year of } \\
\text { transplantation }\end{array}$ & $\begin{array}{l}\text { Median age } \\
\text { (range), } \\
\text { years }\end{array}$ & Disease & Conditioning & $\begin{array}{l}\text { Grade } 3-4 \text { acute } \\
\text { GVHD }\end{array}$ & Overall survival \\
\hline $\begin{array}{l}\text { Rubinstein } \\
\text { et al. [11] }\end{array}$ & 562 & 1993-1998 & $\begin{array}{l}<18 \text { years: } \\
82 \%\end{array}$ & $\begin{array}{l}\text { Any } \\
\text { disease }\end{array}$ & NA & Match $<$ mismatch & NA \\
\hline $\begin{array}{l}\text { Barker } \\
\text { et al. [34] }\end{array}$ & 1,061 & 1993-2006 & $9.3(0-64)$ & $\begin{array}{l}\text { AML/ } \\
\text { ALL/ } \\
\text { CML/ } \\
\text { MDS }\end{array}$ & MAC & $\begin{array}{l}0 \mathrm{MM}<1 \\
\mathrm{MM}<2 \mathrm{MM} \\
3 \mathrm{MM}\end{array}$ & $\begin{array}{l}0 \mathrm{MM}>1 \mathrm{MM} \\
\left(2.5-4.9 \times 10^{7} / \mathrm{kg}\right)>1 \mathrm{MM} \\
\left(<2.5 \times 10^{7} / \mathrm{kg}\right), 2 \mathrm{MM} \\
\left(<2.5 \times 10^{7} / \mathrm{kg}\right), 3 \mathrm{MM}\end{array}$ \\
\hline \multirow[t]{2}{*}{$\begin{array}{l}\text { Atsuta } \\
\text { et al. [35] }\end{array}$} & 498 & 2000-2009 & $5(0-15)$ & $\begin{array}{l}\text { AML/ } \\
\text { ALL/ } \\
\text { CML/ } \\
\text { MDS }\end{array}$ & MAC/RIC & $\begin{array}{l}0 \mathrm{MM}=1 \mathrm{MM}, \\
2 \mathrm{MM}, 3 \mathrm{MM} \\
(2-4 \text { acute } \mathrm{GVHD}: \\
0 \mathrm{MM}<1 \mathrm{MM}, \\
2 \mathrm{MM}, 3 \mathrm{MM})\end{array}$ & $\begin{array}{l}0 \mathrm{MM}=1 \mathrm{MM}, 3 \mathrm{MM} \\
0 \mathrm{MM}>2 \mathrm{MM}\end{array}$ \\
\hline & 1,880 & & $49(16-82)$ & & & $\begin{array}{c}0 \mathrm{MM}=1 \mathrm{MM} \\
2 \mathrm{MM}, 3 \mathrm{MM}\end{array}$ & $0 \mathrm{MM}=1 \mathrm{MM}, 2 \mathrm{MM}, 3 \mathrm{MM}$ \\
\hline $\begin{array}{l}\text { Eapen } \\
\text { et al. [38] }\end{array}$ & 803 & 1996-2008 & $10(0-62)$ & $\begin{array}{l}\text { AML/ } \\
\text { ALL/ } \\
\text { CML/ } \\
\text { MDS }\end{array}$ & MAC & $\begin{array}{l}\text { NA }(2-4 \text { acute } \\
\text { GHVD; } 0 \\
\text { MM }=1,2,3,4 \\
\text { MM) }\end{array}$ & $\begin{array}{l}0 \mathrm{MM}=1,2,3,4 \mathrm{MM} \\
\mathrm{C}-\mathrm{MM}<\mathrm{C}-\text { match (in HLA-A, } \\
\text {-B, -DRB1 one mismatch } \\
\text { group) }\end{array}$ \\
\hline
\end{tabular}

$A M L$ acute myelogenous leukemia, $A L L$ acute lymphoblastic leukemia, $C M L$ chronic myelogenous leukemia, $M D S$ myelodysplastic syndrome, $N A$ not available, MAC, myeloablative conditioning, RIC reduced-intensity conditioning, $M M$ mismatch

that 16 mismatch combinations (four for HLA-A, one for HLA-B, seven for HLA-C, one for HLA-DRB1, one for HLA DRB1/DQB1, and two for HLA-DPB1) are significantly associated with severe acute GVHD. When they are combined as a non-permissive mismatch group and others as a permissive group, the outcomes of HSCT from mismatched unrelated donors without a non-permissive mismatch were comparable to that from 8/8 MUD. One and two or more non-permissive mismatch was significantly associated with higher incidence of severe acute GVHD and overall mortality. They also found that a specific amino acid replacement at a specific position of the HLA-A or HLA-C locus increases the risk of severe acute GVHD, suggesting that allo-reactivity may be influenced by a specific conformational change in the HLA molecule.

\section{Effects of HLA mismatch in UCBT}

The effect of HLA mismatch in UCBT may differ from that in bone marrow or peripheral blood stem cell transplantation, as up to two HLA mismatches can be tolerated and do not affect the success of the transplantation with standard GVHD prophylaxis, and the cellular composition of UCB and bone marrow/peripheral blood stem cells is significantly different.

Rubinstein et al. [11] reported that the incidence of severe acute GVHD was lower in patients receiving HLA-matched UCB than in patients receiving HLA mismatched UCB, but the GVHD risk was not associated with the number of mismatches (Table 3). Barker et al. performed the analysis using larger cohorts $(n=1,061)$ of HSCT using single UCB units from the New York Blood Center. They showed that recipients of HLA-matched UCB had significantly lower incidence of severe acute GVHD than recipients of HLA single-mismatched UCB, whereas recipients of HLA 2-3 mismatched UCB had a higher GVHD incidence [35]. In addition, compared with recipients of single-mismatched UCB containing total nucleated cell doses of $2.5-4.9 \times 10^{7} /$ $\mathrm{kg}$, recipients of HLA-matched UCB showed lower treatment-related mortality and overall morality. These results suggest that HLA-matched UCB, if available, is preferred for reducing GVHD incidence and mortality.

However, the cohorts analyzed in these studies were mostly children or young adults. The effect of HLA disparity may differ in adults, as total nucleated cell doses and doses of other cellular components, such as $\mathrm{T}$ cells, per recipient weight are much lower compared to those in pediatric patients. To reveal the impact of HLA matching in both pediatric and adult cohorts, Atsuta et al. [36] analyzed the impact of HLA mismatch on outcomes of UCBT separately in 498 children and 1,880 adults with leukemia (Table 3). In agreement with the results from the US and European cohorts, the risk of grade 2-4 acute GVHD was significantly increased in pediatric patients receiving HLA mismatched UCB. Patients receiving HLA 2-mismatched UCB showed a significantly increased risk of overall mortality and transplant-related mortality compared to those receiving HLA-matched UCB. Interestingly in adults, in contrast to the results in children, the risks of grade 2-4 
acute GVHD in mismatched UCB recipients did not differ as compared with matched UCB recipients. The risk of mortality did not increase with the number of mismatched loci. This study showed that HLA disparity had little impact on transplant outcomes in adult recipients. These findings should be externally validated in other large adult cohorts. Recently, transplantation using double UCB units has been increasingly performed in adults in the USA and Europe, as it is difficult to find UCB units capable of providing a sufficiently large total nucleated cell dose per recipient weight in adults, since the average adult body weight is higher than that in Asian countries [37, 38]. The impact of HLA mismatch between a recipient and UCB units or between UCB units in double UCBT will also be explored in the future.

\section{Impact of HLA-C mismatch}

Recently, Eapen et al. [39] have analyzed the effects of HLA-C mismatch in UCBT in addition to the standard mismatch counting of HLA-A and HLA-B antigens and HLA-DRB1 allele (Table 3). In this analysis, the risk of grade 2-4 acute GVHD was not significantly associated with the number of HLA mismatches or locus-specific mismatches. Additional HLA-C mismatch did not affect the incidence of acute GVHD. On the other hand, transplantrelated mortality was significantly higher in patients who received a UCB unit matched at the HLA-A, HLA-B, and HLA-DRB1 loci or with a single mismatch at the HLA-A, HLA-B, or HLA-DRB1 locus, if HLA-C was additionally mismatched. This study suggests the need for HLA-C typing and selection of units that are at least HLA-C antigenmatched to reduce treatment-related mortality. Because this study included mostly children and young adults, a separate analysis of adults and children may be needed to extend the interpretation of this finding to adult UCBT.

Impact of HLA mismatch direction

Theoretically, the HLA mismatch direction is important when considering the risk of acute GVHD because UCB mismatched only in the $\mathrm{HVG}$ direction would have a similar risk of acute GVHD as matched UCB. However, we showed that there is no difference between the incidence of acute GVHD according to mismatch direction [40]. The HLA mismatch direction also did not have an impact on overall survival. A similar finding regarding GVHD incidence was reported from the New York Blood Center [41].

HLA mismatch counting criteria

Differences in HLA mismatch counting in UCB unit selection should be considered when interpreting the results of Japan and US/European countries. HLA mismatch counting in clinical practices in US and European countries is at the antigen level for HLA-A and HLA-B and at the allele level for HLA-DRB1, whereas mismatch counting is at the antigen level for HLA-A, HLA-B, and HLA-DR in Japan. There is no robust evidence to support counting of the HLA-DRB1 locus at the allele level. Possibly, an antigen- or allele-level mismatch at the DRB1 locus would not substantially affect clinical outcomes [36, 40]. Differences in the effects of antigen and allele mismatch on UCB outcomes will be extensively studied in the near future. Furthermore, as discussed, an HLA-C mismatch may be added to the standard HLA matching criteria.

\section{Conclusions}

The effect of HLA mismatch differs depending on various factors, such as stem cell source, GVHD prophylaxis, year of transplant, recipient age, and possibly race. Therefore, results should be cautiously interpreted, and clinical decisions should be taken after consideration of all such factors. Importantly, information on the effect of HLA mismatch should be constantly updated using more recent and homogeneous cohorts.

Acknowledgments This work was supported in part by SENSHIN Medical Research Foundation.

Conflict of interest The author declares no competing financial interests.

\section{References}

1. Anasetti C, Beatty PG, Storb R, Martin PJ, Mori M, Sanders JE, et al. Effect of HLA incompatibility on graft-versus-host disease, relapse, and survival after marrow transplantation for patients with leukemia or lymphoma. Hum Immunol. 1990;29:79-91.

2. Anasetti C, Amos D, Beatty PG, Appelbaum FR, Bensinger W, Buckner CD, et al. Effect of HLA compatibility on engraftment of bone marrow transplants in patients with leukemia or lymphoma. N Engl J Med. 1989;320:197-204.

3. Kanda Y, Chiba S, Hirai H, Sakamaki H, Iseki T, Kodera Y, et al. Allogeneic hematopoietic stem cell transplantation from family members other than HLA-identical siblings over the last decade (1991-2000). Blood. 2003;102:1541-7.

4. Szydlo R, Goldman JM, Klein JP, Gale RP, Ash RC, Bach FH, et al. Results of allogeneic bone marrow transplants for leukemia using donors other than HLA-identical siblings. J Clin Oncol. 1997; 15:1767-77.

5. Petersdorf EW, Gooley TA, Anasetti C, Martin PJ, Smith AG, Mickelson EM, et al. Optimizing outcome after unrelated marrow transplantation by comprehensive matching of HLA class I and II alleles in the donor and recipient. Blood. 1998;92:3515-20.

6. Hansen JA, Gooley TA, Martin PJ, Appelbaum F, Chauncey TR, Clift RA, et al. Bone marrow transplants from unrelated donors for patients with chronic myeloid leukemia. N Engl J Med. 1998;338:962-8. 
7. Schetelig J, Bornhauser M, Schmid C, Hertenstein B, Schwerdtfeger R, Martin H, et al. Matched unrelated or matched sibling donors result in comparable survival after allogeneic stem-cell transplantation in elderly patients with acute myeloid leukemia: a report from the cooperative German Transplant Study Group. J Clin Oncol. 2008;26:5183-91.

8. Yakoub-Agha I, Mesnil F, Kuentz M, Boiron JM, Ifrah N, Milpied $\mathrm{N}$, et al. Allogeneic marrow stem-cell transplantation from human leukocyte antigen-identical siblings versus human leukocyte antigen-allelic-matched unrelated donors (10/10) in patients with standard-risk hematologic malignancy: a prospective study from the French Society of Bone Marrow Transplantation and Cell Therapy. J Clin Oncol. 2006;24:5695-702.

9. Kanda J, Saji H, Fukuda T, Kobayashi T, Miyamura K, Eto T, et al. Related transplantation with HLA-1 Ag mismatch in the GVH direction and HLA- $8 / 8$ allele-matched unrelated transplantation: a nationwide retrospective study. Blood. 2012;119: 2409-16.

10. Wagner JE, Rosenthal J, Sweetman R, Shu XO, Davies SM, Ramsay NK, et al. Successful transplantation of HLA-matched and HLA-mismatched umbilical cord blood from unrelated donors: analysis of engraftment and acute graft-versus-host disease. Blood. 1996;88:795-802.

11. Rubinstein P, Carrier C, Scaradavou A, Kurtzberg J, Adamson J, Migliaccio AR, et al. Outcomes among 562 recipients of placental-blood transplants from unrelated donors. N Engl J Med. 1998;339:1565-77.

12. Rocha V, Labopin M, Sanz G, Arcese W, Schwerdtfeger R, Bosi A, et al. Transplants of umbilical-cord blood or bone marrow from unrelated donors in adults with acute leukemia. N Engl J Med. 2004;351:2276-85.

13. Eapen M, Rubinstein P, Zhang MJ, Stevens C, Kurtzberg J, Scaradavou A, et al. Outcomes of transplantation of unrelated donor umbilical cord blood and bone marrow in children with acute leukaemia: a comparison study. Lancet. 2007;369:1947-54.

14. Atsuta Y, Suzuki R, Nagamura-Inoue T, Taniguchi S, Takahashi $\mathrm{S}$, Kai S, et al. Disease-specific analyses of unrelated cord blood transplantation compared with unrelated bone marrow transplantation in adult patients with acute leukemia. Blood. 2009;113:1631-8.

15. Kanda J, Ichinohe T, Kato S, Uchida N, Terakura S, Fukuda T, et al. Unrelated cord blood transplantation vs related transplantation with HLA 1-antigen mismatch in the graft-versus-host direction. Leukemia. 2013;27:286-94.

16. Valcarcel D, Sierra J, Wang T, Kan F, Gupta V, Hale GA, et al. One-antigen mismatched related versus HLA-matched unrelated donor hematopoietic stem cell transplantation in adults with acute leukemia: Center for International Blood and Marrow Transplant Research results in the era of molecular HLA typing. Biol Blood Marrow Transplant. 2010;17:640-8.

17. Morishima S, Ogawa S, Matsubara A, Kawase T, Nannya Y, Kashiwase K, et al. Impact of highly conserved HLA haplotype on acute graft-versus-host disease. Blood. 2010;115:4664-70.

18. Ottinger $\mathrm{H}$, Grosse-Wilde $\mathrm{M}$, Schmitz A, Grosse-Wilde $\mathrm{H}$. Immunogenetic marrow donor search for 1012 patients: a retrospective analysis of strategies, outcome and costs. Bone Marrow Transplant. 1994;14(Suppl 4):S34-8.

19. Aversa F, Terenzi A, Tabilio A, Falzetti F, Carotti A, Ballanti S, et al. Full haplotype-mismatched hematopoietic stem-cell transplantation: a phase II study in patients with acute leukemia at high risk of relapse. J Clin Oncol. 2005;23:3447-54.

20. Lu DP, Dong L, Wu T, Huang XJ, Zhang MJ, Han W, et al. Conditioning including antithymocyte globulin followed by unmanipulated HLA-mismatched/haploidentical blood and marrow transplantation can achieve comparable outcomes with HLAidentical sibling transplantation. Blood. 2006;107:3065-73.
21. Ogawa H, Ikegame K, Kaida K, Yoshihara S, Fujioka T, Taniguchi $\mathrm{Y}$, et al. Unmanipulated HLA 2-3 antigen-mismatched (haploidentical) bone marrow transplantation using only pharmacological GVHD prophylaxis. Exp Hematol. 2008;36:1-8.

22. Rizzieri DA, Koh LP, Long GD, Gasparetto C, Sullivan KM, Horwitz M, et al. Partially matched, nonmyeloablative allogeneic transplantation: clinical outcomes and immune reconstitution. J Clin Oncol. 2007;25:690-7.

23. Luznik L, O'Donnell PV, Symons HJ, Chen AR, Leffell MS, Zahurak M, et al. HLA-haploidentical bone marrow transplantation for hematologic malignancies using nonmyeloablative conditioning and high-dose, posttransplantation cyclophosphamide. Biol Blood Marrow Transplant. 2008;14:641-50.

24. Kanda Y, Oshima K, Asano-Mori Y, Kandabashi K, Nakagawa $\mathrm{M}$, Sakata-Yanagimoto $\mathbf{M}$, et al. In vivo alemtuzumab enables haploidentical human leukocyte antigen-mismatched hematopoietic stem-cell transplantation without ex vivo graft manipulation. Transplantation. 2005;79:1351-7.

25. Kanda J, Lopez RD, Rizzieri DA. Alemtuzumab for the prevention and treatment of graft-versus-host disease. Int J Hematol. 2011;93:586-93.

26. Petersdorf EW, Kollman C, Hurley CK, Dupont B, Nademanee A, Begovich AB, et al. Effect of HLA class II gene disparity on clinical outcome in unrelated donor hematopoietic cell transplantation for chronic myeloid leukemia: the US National Marrow Donor Program Experience. Blood. 2001;98:2922-9.

27. Petersdorf EW, Longton GM, Anasetti C, Martin PJ, Mickelson EM, Smith AG, et al. The significance of HLA-DRB1 matching on clinical outcome after HLA-A, B, DR identical unrelated donor marrow transplantation. Blood. 1995;86:1606-13.

28. Sasazuki T, Juji T, Morishima Y, Kinukawa N, Kashiwabara H, Inoko $\mathrm{H}$, et al. Effect of matching of class I HLA alleles on clinical outcome after transplantation of hematopoietic stem cells from an unrelated donor. Japan Marrow Donor Program. N Engl J Med. 1998;339:1177-85.

29. Morishima Y, Sasazuki T, Inoko H, Juji T, Akaza T, Yamamoto $\mathrm{K}$, et al. The clinical significance of human leukocyte antigen (HLA) allele compatibility in patients receiving a marrow transplant from serologically HLA-A, HLA-B, and HLA-DR matched unrelated donors. Blood. 2002;99:4200-6.

30. Morishima Y, Yabe T, Matsuo K, Kashiwase K, Inoko H, Saji H, et al. Effects of HLA allele and killer immunoglobulin-like receptor ligand matching on clinical outcome in leukemia patients undergoing transplantation with T-cell-replete marrow from an unrelated donor. Biol Blood Marrow Transplant. 2007;13:315-28.

31. Lee SJ, Klein J, Haagenson M, Baxter-Lowe LA, Confer DL, Eapen M, et al. High-resolution donor-recipient HLA matching contributes to the success of unrelated donor marrow transplantation. Blood. 2007;110:4576-83.

32. Kanda Y, Kanda J, Atsuta Y, Maeda Y, Ichinohe T, Ohashi K, et al. Impact of a single human leucocyte antigen (HLA) allele mismatch on the outcome of unrelated bone marrow transplantation over two time periods. A retrospective analysis of 3003 patients from the HLA Working Group of the Japan Society for Blood and Marrow Transplantation. Br J Haematol. 2013;161: 566-77.

33. Flomenberg N, Baxter-Lowe LA, Confer D, Fernandez-Vina M, Filipovich A, Horowitz M, et al. Impact of HLA class I and class II high-resolution matching on outcomes of unrelated donor bone marrow transplantation: HLA-C mismatching is associated with a strong adverse effect on transplantation outcome. Blood. 2004;104:1923-30.

34. Kawase T, Morishima Y, Matsuo K, Kashiwase K, Inoko H, Saji $\mathrm{H}$, et al. High-risk HLA allele mismatch combinations responsible for severe acute graft-versus-host disease and implication for its molecular mechanism. Blood. 2007;110:2235-41. 
35. Barker JN, Scaradavou A, Stevens CE. Combined effect of total nucleated cell dose and HLA match on transplantation outcome in 1061 cord blood recipients with hematologic malignancies. Blood. 2010;115:1843-9.

36. Atsuta Y, Kanda J, Takanashi M, Morishima Y, Taniguchi S, Takahashi S, et al. Different effects of HLA disparity on transplant outcomes after single-unit cord blood transplantation between pediatric and adult patients with leukemia. Haematologica. 2013;98:814-22.

37. Sideri A, Neokleous N, De La Grange PB, Guerton B, Le Bousse Kerdilles MC, Uzan G, et al. An overview of the progress on double umbilical cord blood transplantation. Haematologica. 2011; 96:1213-20.

38. Scaradavou A, Brunstein CG, Eapen M, Le-Rademacher J, Barker JN, Chao N, et al. Double unit grafts successfully extend the application of umbilical cord blood transplantation in adults with acute leukemia. Blood. 2013;121:752-8.

39. Eapen M, Klein JP, Sanz GF, Spellman S, Ruggeri A, Anasetti C, et al. Effect of donor-recipient HLA matching at HLA A, B, C, and DRB1 on outcomes after umbilical-cord blood transplantation for leukaemia and myelodysplastic syndrome: a retrospective analysis. Lancet Oncol. 2011;12:1214-21.

40. Kanda J, Atsuta Y, Wake A, Ichinohe T, Takanashi M, Morishima $\mathrm{Y}$, et al. Impact of the direction of HLA mismatch on transplantation outcomes in single unrelated cord blood transplantation. Biol Blood Marrow Transplant. 2013;19:247-54.

41. Stevens CE, Carrier C, Carpenter C, Sung D, Scaradavou A. HLA mismatch direction in cord blood transplantation: impact on outcome and implications for cord blood unit selection. Blood. 2011;118:3969-78. 